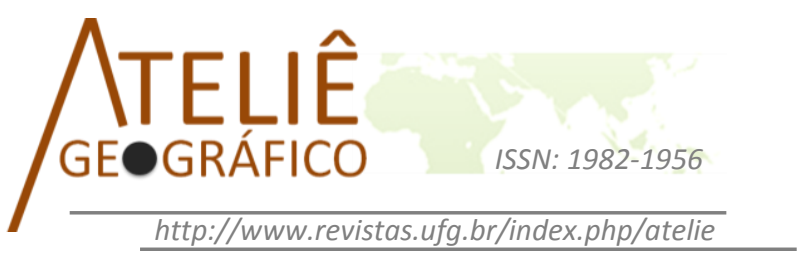

\title{
Dinámica migratoria y desempleo en la Argentina (1991-2010)
}

\author{
Dynamics of migration and unemployment in \\ Argentina (1991-2010)
}

\author{
Dinâmicas migratórias e desemprego \\ na Argentina (1991 -2010)
}

Fernando Ariel Manzano

Universidad Nacional de Moreno, Argentina

fernando14979@hotmail.com

Guillermo Ángel Velázquez

Universidad Nacional del Centro de la Provincia de Buenos Aires

gvelaz@fch.unicen.edu.ar

\begin{abstract}
Resumen
A lo largo de este trabajo analizamos las desigualdades en la tasa de actividad entre las provincias de Argentina durante el periodo 1991-2010. Las teorías afines a la lógica del "mercado" consideran que la libre movilidad de los factores, equilibraría los mercados laborales de las distintas provincias. Los datos de la realidad muestran que estas diferencias tienden cristalizarse en el tiempo. El comportamiento de la dinámica migratoria, lejos está de mejorar la situación, más bien tiende a empeorar las condiciones iniciales del mercado laboral, y es responsable en cierta medida de la perpetuación de las asimetrías entre las regiones más desarrollados y las más postergadas.
\end{abstract}

Palabras claves: mercado de trabajo, desigualdades regionales, tasa de actividad, migraciones.

\footnotetext{
Abstract

The aim of this study was to analyze the inequalities observed in the activity rate between Argentine provinces in the 1991-2010 period. According to theories in line with the logic of the "market," the free movement of factors could balance the labor markets of the different provinces. As shown by factual data, these differences tend to become more marked over time. Far from improving the situation, the behavior of
} 
migratory dynamics tends, instead, to worsen the initial conditions of the labor market. It is also responsible to some extent for perpetuating the asymmetries existing between the most and least developed regions.

Key words: labor market, regional inequalities, activity rate, migrations.

\begin{abstract}
Resumo
Neste artigo analisamos as desigualdades na taxa de atividade entre as províncias da Argentina entre os anos de 1991 e 2010. As teorias aparentadas com a lógica do "mercado" acreditam que a livre mobilidade dos fatores equilibraria os mercados de trabalho das diferentes províncias. Os dados da realidade mostram que estas diferenças tendem cristalizar ao longo do tempo. O comportamento das dinâmicas migratórias não melhora a situação, mas tende a piorar as condições iniciais do mercado de trabalho e é responsável, em certa medida, pela perpetuação das assimetrias entre as regiões mais desenvolvidas e mais pobres.

Palavras-chave: mercado de trabalho, disparidades regionais, taxas de emprego,
\end{abstract} migrações.

\title{
Introducción
}

Las diferencias regionales se constituyen en una constante del devenir de la economía-mundo capitalista; las distintas fases de desenvolvimiento del sistema económico estructuran de manera desigual el espacio geográfico, generando así procesos de divergencia social y regional que responden a una lógica de acumulación determinada por fuerzas tanto exógenas como endógenas. Consideramos así que la desigualdad "no es una antesala de la igualdad, como el desequilibrio lo es en los modelos económicos tradicionales" (ROFMAN, 1974 p.71).

Las teorías afines a la lógica del "mercado" parten desde el contexto general de la teoría económica neoclásica, y asignan a la movilidad de los factores capital y trabajo la responsabilidad de lograr niveles igualitarios en el desarrollo regional. Por tanto, los movimientos interregionales del capital y del trabajo como respuesta a los estímulos del mercado compensarían de una $\mathrm{u}$ otra manera las situaciones de desigualdad, impidiendo que persistan en el tiempo

Mientras que las teorías estructurales priorizan al mercado como agente de divergencia; el intercambio y la libre movilidad de factores no generarían niveles relativos de igualdad: por el contrario, exacerbarían las desigualdades preexistentes. En el mismo sentido la teoría de la acusación circular acumulativa plantea, que el libre juego de las fuerzas de mercado tendería a aumentar, más que a disminuir, las desigualdades entre las regiones; el sistema no se movería hacia ningún equilibrio entre fuerzas, la expansión de una región dada se produciría en detrimento del desarrollo de otras, y uno de los medios a través a de los cuales se retroalimenta este proceso de desigualdad es por medio de las migraciones.

A diferencia de los periodos de finales del siglo XIX y mediados del XX donde el crecimiento poblacional estaba sujeto al fuerte saldo migratorio neto con los países no limítrofes. En las últimas décadas la migración internacional está compuesta en su mayor parte por los migrantes limítrofes. Su incidencia no ha variado a lo largo 
de la serie histórica, reflejando que han venido ocurriendo desde larga data. Sin embargo a diferencia de la tendencia histórica Argentina, en el periodo 1991-2010 se ha tenido un saldo migratorio internacional negativo. Por lo tanto, las variaciones en las tasas de crecimiento provinciales durante este periodo tienen como causa dominante las tendencias diferenciales en la fecundidad y en menor medida la migración interna.

El objetivo de este trabajo busca corroborar empíricamente, cuales es la relación entre la dinámica migratoria y el nivel de desempleo, y establecer cuál es la teoría que mejor se adapta a la realidad de los hechos.

\section{Teorías sobre las diferencias del desarrollo regional}

Las diferencias regionales se constituyen en una constante del devenir de la economía-mundo capitalista; las distintas fases de desenvolvimiento del sistema económico estructuran de manera desigual el espacio geográfico, generando así procesos de divergencia social y regional que responden a una lógica de acumulación determinada por fuerzas tanto exógenas como endógenas. Consideramos así que la desigualdad "no es una antesala de la igualdad, como el desequilibrio lo es en los modelos económicos tradicionales" (ROFMAN, 1974 p.71). Existen entonces dos versiones de la idea de desequilibrio regional, centradas en torno a una configuración espacial dada, que se supone está desajustada: una considera indeseable la presencia de fuertes desniveles en los valores promedio de cada subespacio; la otra, en cambio, estima que la situación que se describe proviene de la ruptura de una supuesta posición de equilibrio. Sin embargo, dicho desequilibrio no es más que un desajuste coyuntural provocado por el devenir del libre juego de fuerzas del mercado, y cuya magnitud es lo suficientemente pequeña como para ser revertido o neutralizado por una modificación también coyuntural- en las relaciones de oferta y demanda: el equilibrio se produce automáticamente, en tanto al sistema productivo le sea permitido operar libremente, mientras que el "desequilibrio" sería, por definición, algo transitorio y, por tanto, no aplicable a situaciones de mediano o largo plazo (VELÁZQUEZ, 2001 p.32). Las desigualdades regionales, en cambio, se refieren a aquellas diferencias durables, localmente interdependientes y acumulativas entre subespacios de un mismo país en las que condiciones no solamente coyunturales sino también estructurales son responsables por las numerosas asimetrías ligadas unas a las otras, en la escala del espacio considerado (SANTOS, 1979 p.230-1). De esta manera, la identificación de la noción de equidad o igualdad en las disciplinas sociales surge de constatar su ausencia o inexistencia entre promedios de los principales fenómenos socioeconómicos. El predominio de un modo de producción capitalista implica, por definición, una participación diferenciada en la distribución de la riqueza, fenómeno estructural que tiñe con un contenido de desigualdad a todas las demás instancias. Al comparar el ingreso medio por habitante de dos provincias estamos comparando, en realidad, dos desigualdades, ya que el grado de heterogeneidad social a nivel provincial suele ser enorme.

A continuación, agruparemos a las principales teorías sobre las desigualdades regionales en dos vertientes: la primera se refiere a las teorías afines a la lógica del mercado; la segunda vinculada con enfoques de carácter estructural. 
Las teorías afines a la lógica del "mercado" parten desde el contexto general de la teoría económica neoclásica, y asignan a la movilidad de los factores capital y trabajo la responsabilidad de lograr niveles igualitarios en el desarrollo regional. El factor trabajo tendería a desplazarse hacia las regiones de mayor desarrollo relativo, atraído por menores índices de desempleo y mayores niveles salariales, mientras que el factor capital tendería a movilizarse hacia aquellas regiones que ostentan menores niveles de desarrollo relativo, ya que en éstas -debido a los bajos niveles salariales de la mano de obra y capital per cápita-, es posible obtener mayores tasas de rendimiento marginal. Por tanto, los movimientos interregionales del capital y del trabajo como respuesta a los estímulos del mercado compensarían de una $u$ otra manera las situaciones de desigualdad, impidiendo que persistan en el tiempo, y generando un rápido incremento de la productividad y de la acumulación de capital (CEÑA DELGADO, 1995 p.94).

El modelo neoclásico de igualación de factores señala al libre comercio como la fuerza de mercado que anularía las diferencias gestadas por la naturaleza, la dinámica demográfica interna y los mercados regionales de trabajo, compensando así accidentes, errores y omisiones de la dotación inicial y evolución histórica. Si alguna de las regiones constitutivas del sistema decidiera restringir la movilidad del capital y del trabajo, éstos se verían impedidos de fluir libremente, generando así una desigualdad relativa. Resultaría así vital intercomunicar a las regiones a los fines de transmitir estímulos de crecimiento de un ámbito espacial a otro y extender el efecto multiplicador del crecimiento desde las regiones más privilegiadas a las de menor desarrollo relativo: un mercado libre y la ausencia de restricciones al movimiento interno de factores productivos tienden a igualar los desniveles de ingreso interregionales originados inicialmente en una dotación desigual de recursos.

El modelo del aprovechamiento de los recursos naturales en el espacio intenta explicar las desigualdades regionales sobre la base de la dotación de recursos aprovechables emplazados en una región dada que deben ser movilizados en función de la selectividad de la demanda extrarregional. Aquí subyace implícitamente el supuesto de la existencia de ventajas comparativas para la producción regional y la ausencia de restricciones respecto de la libre localización del capital y la mano de obra. Así, el crecimiento regional respondería a la libre concurrencia de la oferta de recursos naturales y las cambiantes modalidades de los requerimientos extrarregionales, los que se ajustan al proceso productivo dominante en cada etapa histórica del desarrollo nacional. Sin embargo, la ventaja comparativa muy raramente es una cuestión de dotación inicial y menos aún natural. La ventaja comparativa es artificial (BENKO, 1996 p.56).

El modelo de desarrollo evolutivo de Rostow postula que todo sistema económico-social atravesaría (inexorablemente), por una serie de estadios definidos en función de indicadores macroeconómicos, seleccionados para representar objetivamente los niveles de desarrollo relativo alcanzados por distintas unidades espaciales; partiendo desde una concepción desarrollista y aislacionista, la desigualdad sería el mero producto de la coexistencia de regiones en diferentes etapas de la evolución. Esta coexistencia se derivaría de la tardía inserción a las estructuras del mercado mundial de territorios recientemente descolonizados. Sólo el paso del tiempo y la difusión del desarrollo desde 
las regiones más evolucionadas compensarían las situaciones de desigualdad, puesto que el "despegue" no sería más que un problema de reformas internas.

La teoría del dualismo estructural señala que en todo sistema espacial coexisten dos sociedades de dinámicas disímiles y contrapuestas: una sociedad moderna e innovadora y otra tradicional y conservadora, una estructura en movimiento y otra cristalizada en el tiempo a partir de las cuales se genera un dualismo estructural generalmente vinculado a la coexistencia de formas de producción capitalistas con otras con fuerte nivel de atraso o precapitalistas cuyo origen reside en la implantación de un núcleo modernizador, un enclave, en un tejido social débil y desestructurado. Así, "la ciudad comienza ser visualizada como una estructura modernizante, apta para irradiar la innovación y el desarrollo hacia las áreas rurales tradicionales" (ROFMAN, 1974 p.91). De esta manera, se identificó al sector atrasado "con la agricultura o, por lo menos, con una fracción considerable de esta última”. (ASTORI, 1982 p.57).

La teoría del crecimiento o el desarrollo endógeno constituye un nuevo enfoque dentro de la vertiente funcional. Parte del supuesto básico que el crecimiento es una condición necesaria, aún cuando no suficiente, para el desarrollo (DE MATTOS, 1996 p.2). El crecimiento de las regiones se debería fundamentalmente a su dinámica interna, y no a factores exógenos; si bien éstos condicionan el proceso, se afirma no son suficientes para imponer obstáculos tales que la fuerza endógena coordinada e integrada de un territorio dado no pueda superar. El desarrollo regional dependería de la capacidad de cada región de activar su potencial endógeno y mantenerlo sobre la base de la interacción con procesos exógenos al territorio en cuestión, regulando los procesos de manera flexible, acorde al paradigma en vigencia; sólo así las regiones podrán lograr una inserción favorable en un contexto fragmentado, jerarquizado y desigual.

Las teorías estructurales priorizan al mercado como agente de divergencia; el intercambio y la libre movilidad de factores no generarían niveles relativos de igualdad: por el contrario, exacerbarían las desigualdades preexistentes. Crítico hacia la ortodoxia neoclásica imperante, el enfoque centro-periferia, distingue la presencia de dos polos, diferenciados sustancialmente: el centro, homogéneo y diversificado, frente a una periferia cuya estructura productiva se encuentra sustentada en la comercialización de bienes primarios, con un basamento estructural débil y heterogéneo. La desigualdad residiría en el declive secular de los términos del intercambio, dado por la baja elasticidad de la demanda de los productos exportados por la periferia, y el control del progreso técnico esbozado por parte del centro.

La teoría de la causación circular acumulativa plantea, por su parte, que el libre juego de las fuerzas de mercado tendería a aumentar, más que a disminuir, las desigualdades entre las regiones; el sistema no se movería por sí mismo hacia ningún equilibrio entre fuerzas, sino que se estaría alejando constantemente de tal posición (MYRDAL, 1957 p.25-30). La expansión de una región dada se produciría en detrimento del desarrollo de otras, pues el crecimiento económico debe comenzar sólo en algunas y no en todas las regiones del espacio geográfico (HOLLAND, 1976 p.16). Las migraciones serían uno de "los medios a través de los cuales evoluciona el proceso acumulativo en forma ascendente en las regiones con suerte y en forma descendente en las desfavorecidas" (MYRDAL, 1957 p.39), retroalimentando el proceso de 
desigualdad. La aparición de efectos de difusión permitiría una lenta descentralización de ciertas actividades económicas y movimientos migratorios, los cuales abandonarían su localización originaria para desplazarse hacia áreas circundantes y accesibles.

La teoría de los polos de crecimiento parte del supuesto que el crecimiento económico no se produce nunca de modo uniforme, sino que surge en determinados lugares que reúnen condiciones particularmente favorables para que se instalen en ellos actividades motrices, generalmente industriales y muy dinámicas que ofrecen elevadas economías externas y de aglomeración. Generarían la polarización de las inversiones y los ingresos al construir una imagen territorial favorable a la inversión privada (disminución de riesgos, maximización de la tasa de beneficio).

La teoría de la división espacial del trabajo, por su parte, representa un punto de inflexión al interior de la vertiente crítica del desarrollo regional; sustentada en la teoría de los sistemas mundiales y heredera de la teoría centro-periferia, cuestiona el mecanicismo de una visión dual demasiado estructurada que supone una profundización constante y sin modificaciones en su localización respectiva de los procesos de desarrollo y subdesarrollo. Esto impediría explicar algunos cambios recientes, como el declive de regiones industrializadas y la emergencia de nuevos países y regiones dinámicos antes encuadrados en el área del subdesarrollo (MÉNDEZ, 1997 p.349). Así, las coyunturas impredecibles del mercado y las variaciones en las condiciones técnicoproductivas y de regulación social determinarían para cada región un futuro de expansión o de declive. El proceso es dinámico, marcado por sucesivas crisis y rupturas a través de las cuales se producirían cambios sustanciales en la configuración espacial del desarrollo, identificándose espacios centrales, periféricos y semiperiféricos, los cuales serían consagrados durante el tiempo en que impera una determinada división territorial del trabajo a ser áreas de producción moderna. Si el orden global cambia, cada región podrá, eventualmente, continuar con el desarrollo de esa función, más ésta se tornará obsoleta. Así, la naturaleza de las desigualdades regionales sería cambiante, pues nada escaparía a la división espacial del trabajo y su particular amalgamamiento a las estructuras territoriales preexistentes. La nueva región se tornaría más rígida, más específica y menos polivalente, pues los espacios regionales merman su capacidad de producir múltiples objetos para afirmar su especialización en pocos productos. Se convierten en altamente productivos, unifuncionales $\mathrm{y}$, por tanto, inestables (SILVEIRA, 1997 p.274-428). Así, surgen nuevas categorías de análisis en los procesos de generación de la desigualdad regional en el desarrollo socioeconómico (la semiperiferia, los espacios excluidos), acordes al proceso contemporáneo de intensa fragmentación territorial.

\section{Algunas consideraciones metodológicas}

El abordaje de las desigualdades regionales implica ciertas dificultades metodológicas. La primera de ellas apunta a que los cambios en el trazado de las fronteras de entidades geográficas tienen gran repercusión sobre los valores alcanzados en ellas por una variable, sin que haya realmente cambiado el valor subyacente del hecho temático. Así es posible, por ejemplo, hacer "desaparecer estadísticamente" a la pobreza modificando y reagrupando las unidades espaciales; sin embargo resultaría 
imposible crear "estadísticamente", mediante el mismo procedimiento, pobreza en donde no existe. A este fenómeno se lo conoce como el problema de la Unidad Espacial Modificable (PUEM). Una segunda dificultad proviene del proceso paralelo de incremento del grado de desagregación espacial y merma en la disponibilidad de información estadística. Si aumentáramos el nivel de análisis espacial, efectuando una comparación entre departamentos, probablemente los resultados obtenidos se acerquen más a la realidad; pero para ello sería mejor aún utilizar unidades espaciales "ad hoc", probablemente más pequeñas aún, y que respondan a una real diferenciación social.

Procurando establecer un cierto grado de correlación entre la dinámica migratoria y los niveles de expulsión de fuerza de trabajo del proceso productivo, hemos procedido al cálculo de los saldos migratorios a partir de la ecuación demográfica básica para la totalidad de las provincias, para luego estimar la situación relativa del mercado de trabajo de cada jurisdicción sobre la base de los datos de los Censos Nacionales de Población, a escala provincial.

\section{Aporte del componente vegetativo y migratorio al crecimiento total nacional}

La evolución de la dinámica demográfica de la Argentina muestra profundos cambios a lo largo de la historia, tanto en el nivel y ritmo de crecimiento como en el papel que jugaron los factores que la determinan. Las estimaciones realizadas por Lattes $^{1}$ (1975) para el periodo pre-censal muestran que el crecimiento de la población fue lento e irregular hasta fines del siglo XVIII, cuando alcanza un nivel medio de $10 \%$ anual. Un siglo más tarde, alrededor de 1870, el ritmo de crecimiento se había triplicado.

Entre los años 1870 y 1914 se da un aumento de la población a una tasa de crecimiento ascendente, después en el periodo 1914-1947 continuo un moderado crecimiento, y con un ritmo de crecimiento aun más leve se transita el periodo que va desde el año 1960 hasta el año 1991.

Durante los dos últimos periodos intercensales, el crecimiento poblacional se mantiene relativamente constante. La tasa de crecimiento medio anual del periodo 1991-2001 fue de 10,6 \%o (se pasa de 32.615.528 habitantes en 1991 a 36.260.130 en 2001). En el último periodo censal la tasa tuvo una suba, aunque poco significativa, de $11,2 \%$ durante el periodo 2001-2010 ( de 36.260.130 habitantes en 2001 a 40.117.096 en 2010). Una mirada de largo plazo acerca de la evolución poblacional en Argentina destaca una tendencia descendente en la tasa de crecimiento anual medio, con pequeñas oscilaciones, desde el año 1869 al año 2010. Tal como se observa en el Figura $\mathrm{N}^{\circ} 1$.

\footnotetext{
${ }^{1}$ Lattes, Alfredo (1975): "Perspectiva histórica de la evolución de la población" en La Población de Argentina, INDEC, Serie de Investigaciones Demográficas $\mathrm{N}^{\circ} 1$
} 


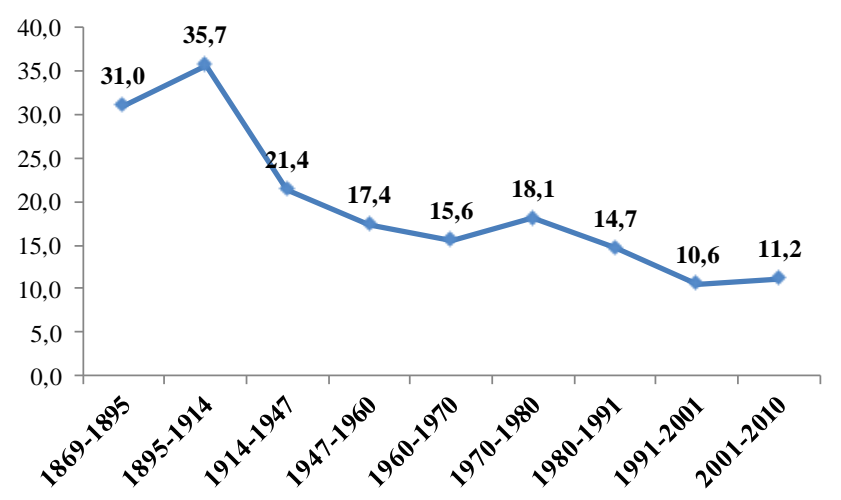

Figura 1: Tasa de crecimiento poblacional anual medio (por mil). Total del país. Años 1869/2010.

Fuente: Elaboración personal en base a datos de los Censos de Población de 1869 a 2010, INDEC.

El análisis de la evolución de los componentes del crecimiento total, comprende la suma del crecimiento vegetativo y el crecimiento migratorio -saldo entre la inmigración y la emigración. Sí el saldo migratorio presenta signo positivo, nos indica que el país es un área de atracción poblacional frente al resto mundo; es decir, el número de inmigrantes supera al de emigrantes. En el caso contrario, se trataría de un área de expulsión, donde el número de emigrantes excede al de inmigrantes.

Durante la etapa que va de 1870 a 1930, el enorme crecimiento de la población se explicaba en un $63 \%$ por el crecimiento vegetativo o natural y el $37 \%$ restante por el aporte del saldo migratorio. Siendo el componente vegetativo mucho más estable en relación al comportamiento del componente migratorio.

Durante el periodo 1930 a 1960, en promedio el aporte del saldo migratorio se reduce a tan solo $15 \%$ del crecimiento total de la población, por tanto el $85 \%$ restante se debe al crecimiento vegetativo. Entre los años 1960 y 1990 estas proporciones en promedio se reducen al $5 \%$ y 95\%, respectivamente. Ver Figura $\mathrm{N}^{\circ} 2$. 


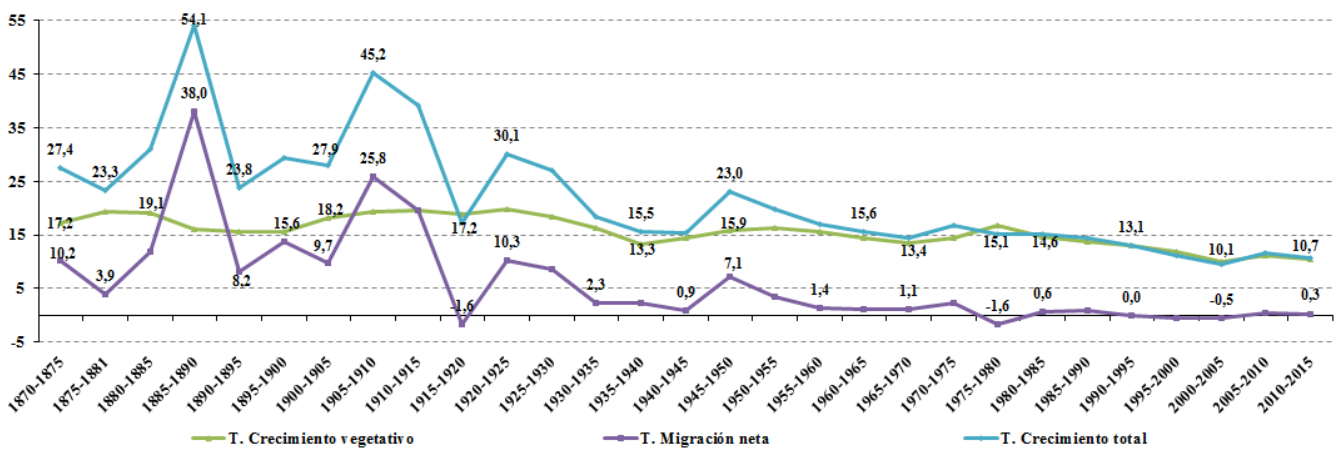

Figura 2: Crecimiento total de la población, migración neta y crecimiento vegetativo, períodos quinquenales. Argentina 1870-2015.

Fuente: Elaboración personal en base a 1870/1930: Lattes (1975); 1930/1950: Recchinni de Lattes (1999), 1950/2005: Estimaciones y proyecciones de población. Total del país. 1950-2015. Serie análisis demográfico $\mathrm{N}^{\circ} 30$, Centro Latinoamericano y Caribeño de Demografía División de Población Serie OI $\mathrm{N}^{\circ} 212$ e Instituto Nacional de Estadística y Censos -(INDEC, 2004). 2010: Estimaciones y proyecciones de población 2010-2040. Total del país. Instituto Nacional de Estadística y Censos -(INDEC, 2013).

Históricamente la tasa de migración neta del país ha sido positiva, con excepción del quinquenio 1975-1980, en donde se alcanzan niveles muy bajos pero positivos durante la década de 1980.

Para la década del 90 las proyecciones demográficas suponían saldos migratorios positivos para el período 1990-2015 (INDEC-CELADE, 1995). Sin embargo, el análisis de la información del Censo 2001 demostró que esos supuestos inmigratorios estaban lejos de cumplirse, en lugar de producirse un ingreso de migrantes internacionales, el saldo migratorio estimado resultó ser negativo en 100.000 personas. El último periodo censal 2001-2010, presentó nuevamente un saldo emigratorio, una salida del país de 45.103 personas ${ }^{3}$.

\section{La heterogeneidad demográfica entre las provincias}

Los indicadores analizados hasta el momento corresponden al promedio nacional y esconden marcadas diferencias internas, como consecuencia de las distintas etapas por la que atraviesan las regiones y provincias.

Podemos observar la heterogeneidad presente en la tasa de crecimiento medio anual de las provincias, y valernos del cálculo de la distancia entre el valor de cada provincia y el promedio nacional, como forma de medir esta variabilidad. A pesar, de que como comentamos a nivel nacional, la tasa anual media tiende a descender en el tiempo, la desigualdad en el crecimiento entre las provincias no ha disminuido.

\footnotetext{
${ }^{2}$ Se consideraron 120.000 inmigrantes para cada uno de los quinquenios del período 1990-2005; 80.000 para el quinquenio 2005-2010 y 40.000 personas para el quinquenio 2010-2015 (INDEC-CELADE, 1995)

${ }^{3}$ Estimaciones y proyecciones de población 2010-2040. : total del país. - 1a ed. - Ciudad Autónoma de Buenos Aires: Instituto Nacional de Estadística y Censos - INDEC, 2013.
} 
Se destacan en términos de crecimiento poblacional, las provincias de la región Patagónica durante el periodo 1970-2010 , por ser la de crecimiento más alto, con excepción del periodo 1991-2001, donde solo continúa destacándose por su crecimiento la provincia de Tierra del Fuego. Así mismo, estas provincias son también las que presentan la mayor volatilidad en su crecimiento, debido a que este depende en mayor proporción del componente migratorio.

En el otro extremo, la jurisdicción de menor crecimiento poblacional es la Ciudad Autónoma de Buenos Aires. También se destaca por mantener esta posición relativa durante los cuatros últimos censos nacionales de población. Sin embargo, eso no hace que su crecimiento tienda a ser estable (por ejemplo en el periodo inter-censal 1991-2001 la tasa de crecimiento anual medio fue de $-6,6 \%$, mientras que en el periodo 2001-2010 ha sido de 4,5\%). Ver Tabla I.

Tabla I: Ritmo de crecimiento de la población, según división provincial.

Periodo1970-2010.

\begin{tabular}{l|c|c|c|c}
\hline \multicolumn{1}{c|}{ División político-territorial } & \multicolumn{4}{|c}{ Tasa de crecimiento anual medio (\%.) } \\
\hline & $1970 / 80$ & $1980 / 90^{1}$ & $1991 / 01$ & $2001 / 10$ \\
\hline Valor total del país & $\mathbf{1 8 , 0}$ & $\mathbf{1 5 , 8}$ & $\mathbf{1 0 , 6}$ & $\mathbf{1 1 , 2}$ \\
\hline
\end{tabular}

Diferencia con respecto al total país

\begin{tabular}{l|c|c|c|c}
\hline Buenos Aires & 1,2 & 1,0 & 0,9 & 1,2 \\
\hline CABA & $-0,1$ & 0,2 & $-0,6$ & 0,4 \\
\hline Catamarca & 1,0 & 1,5 & 2,2 & 0,9 \\
\hline Chaco & 1,2 & 1,2 & 1,5 & 0,7 \\
\hline Chubut & 1,8 & 1,9 & 1,4 & 2,1 \\
\hline Córdoba & 0,9 & 0,9 & 1,0 & 0,8 \\
\hline Corrientes & 0,9 & 1,2 & 1,5 & 0,6 \\
\hline Entre Ríos & 0,6 & 0,8 & 1,2 & 0,6 \\
\hline Formosa & 1,3 & 1,9 & 1,9 & 0,8 \\
\hline Jujuy & 1,7 & 1,4 & 1,7 & 0,9 \\
\hline La Pampa & 1,1 & 1,4 & 1,3 & 0,6 \\
\hline La Rioja & 1,0 & 1,9 & 2,6 & 1,4 \\
\hline Mendoza & 1,2 & 1,1 & 1,1 & 1,0 \\
\hline Misiones & 1,6 & 1,8 & 1,9 & 1,3 \\
\hline Neuquén & 2,6 & 2,9 & 1,9 & 1,5 \\
\hline Río Negro & 2,1 & 1,8 & 0,8 & 1,4 \\
\hline Salta & 1,5 & 1,7 & 2,1 & 1,2 \\
\hline San Juan & 1,1 & 0,8 & 1,5 & 0,9 \\
\hline
\end{tabular}




\begin{tabular}{l|c|c|c|c}
\hline \multicolumn{1}{c|}{ División político-territorial } & \multicolumn{4}{|c}{ Tasa de crecimiento anual medio (\%.) } \\
\hline & $1970 / 80$ & $1980 / 90^{1}$ & $1991 / 01$ & $2001 / 10$ \\
\hline Valor total del país & $\mathbf{1 8 , 0}$ & $\mathbf{1 5 , 8}$ & $\mathbf{1 0 , 6}$ & $\mathbf{1 1 , 2}$ \\
\hline
\end{tabular}

Diferencia con respecto al total país

\begin{tabular}{l|c|c|c|c}
\hline San Luis & 0,9 & 1,8 & 2,4 & 1,6 \\
\hline Santa Cruz & 1,7 & 2,1 & 2,0 & 3,3 \\
\hline Santa Fe & 0,8 & 0,8 & 0,7 & 0,6 \\
\hline Santiago del Estero & 1,0 & 0,8 & 1,7 & 0,8 \\
\hline Tierra del Fuego & 3,2 & 5,9 & 3,6 & 2,3 \\
\hline Tucumán & 1,3 & 1,0 & 1,5 & 0,8 \\
\hline Coeficiente de Variación & 49,3 & 67,9 & 49,5 & 54,6 \\
\hline
\end{tabular}

Fuente: Elaboración personal sobre la base de los Censos Nacionales de Población 1970, 1980, 1991,2001 y 2010 (INDEC).

Otras provincias que por su bajo crecimiento poblacional deben destacarse son: Entre Ríos (fue la segunda provincia de menor crecimiento en 1980 y 1991) y Santa Fe (la segunda provincia de menor crecimiento durante el periodo 2001-2010).

A diferencia de los periodos de finales del siglo XIX y mediados del XX donde el crecimiento poblacional estaba sujeto al fuerte saldo migratorio neto con los países no limítrofes, en las últimas décadas las variaciones en las tasas de crecimiento tienen como causa dominante las tendencias diferenciales en la fecundidad, con la excepción de las provincias patagónicas, en donde el aporte migratorio (en mayor medida la migración interna en relación a la externa) sigue teniendo un rol importante.

A continuación analizaremos el impacto del componente migratorio, desagregado en su parte de migración interna interprovincial y la correspondiente a la migración internacional en las poblaciones provinciales. Con respecto a la migración internacional, esta alcanzó su máxima expresión en 1914, cuando llegaron a representar el $30 \%$ de la población, gracias al volumen que lograron los flujos de ultramar durante ese periodo. A partir de entonces, el porcentaje de nacidos en otros países comienza a decrecer.

La migración internacional está compuesta ahora en su mayor parte por los migrantes limítrofes. Su incidencia no ha variado a lo largo de la serie histórica, reflejando que han venido ocurriendo desde larga data. No obstante, como consecuencia del cambio en la composición de las corrientes internacionales, su cuota entre los extranjeros se ha ido elevando en las tres últimas décadas. En el censo de 1991, los migrantes limítrofes constituyen el 2,5\% (el 50,0\% del total extranjeros) de los 32,6 millones de personas enumeradas en el censo de ese año. En el año 2001 nuevamente los inmigrantes limítrofes representan el 2,5\% (el 60,4\% del total extranjeros) de 36,2 millones de personas y en el año 2010 son el 3,1\% (el 68,9\% del total extranjeros) de los 40,1 millones de personas.

Como vemos en la tabla II vemos que las provincias de la Patagonia, junto a CABA y Buenos Aires son las que presentan históricamente el menor porcentaje de 
población no migrante. En el caso más extremo se encuentra la provincia de Tierra del Fuego, presenta como promedio de porcentaje no migrantes sobre el total de su población, durante el periodo 1980-2010 tan solo 31,6\%.

Tabla II: Distribución porcentual de la población por condición migratoria, según división provincial. Periodo1980-2010

\begin{tabular}{|c|c|c|c|c|c|c|c|c|c|c|c|c|}
\hline \multirow{2}{*}{$\begin{array}{l}\text { División político- } \\
\text { territorial }\end{array}$} & \multicolumn{4}{|c|}{ No Migrantes } & \multicolumn{4}{|c|}{ Migrantes internos ${ }^{(1)}$} & \multicolumn{4}{|c|}{ Migrantes externos $^{(2)}$} \\
\hline & 1980 & 1991 & 2001 & 2010 & 1980 & 1991 & 2001 & 2010 & 1980 & 1991 & 2001 & 2010 \\
\hline & 70,6 & 75,5 & 76,7 & $\mathbf{7 4 , 7}$ & 22,6 & 19,5 & 19,0 & 20,8 & 6,8 & , & 2 & 4,5 \\
\hline Buenc & 58,0 & 66,9 & 68,8 & 67,6 & 33,4 & 26,9 & 25,7 & 26,4 & 8,6 & 6,2 & 5,5 & 6,0 \\
\hline Capital Federal & 62,8 & 66,6 & 56,7 & 59,5 & 23,7 & 22,7 & 31,8 & 27,3 & 13,5 & 10,7 & 11,4 & 13,2 \\
\hline Catan & 87,6 & 86,1 & 85,5 & 89,7 & 11,9 & 13,4 & 14,1 & 9,9 & 0,5 & 0,4 & 0,4 & 0,4 \\
\hline Chaco & 80,5 & 85,9 & 89,6 & 87,0 & 17,1 & 12,8 & 9,6 & 12,4 & 2,4 & 1,4 & 0,8 & 0,6 \\
\hline Chubut & 64,6 & 66,0 & 70,2 & 84,5 & 24,1 & 25,2 & 23,1 & 9,4 & 11,3 & 8,8 & 6,7 & 6,1 \\
\hline Córdoba & 83,5 & 85,5 & 86,5 & 90,2 & 14,0 & 13,0 & 12,2 & 8,3 & 2,5 & 1,5 & 1,3 & 1,5 \\
\hline Corrientes & 88,7 & 88,5 & 89,2 & 71,6 & 10,0 & 10,5 & 10,0 & 27,6 & 1,3 & 1,0 & 0,8 & 0,8 \\
\hline Entre Ríos & 91,3 & 91,7 & 91,3 & 90,0 & 7,3 & 7,3 & 8,0 & 9,1 & 1,4 & 0,9 & 0,7 & 0,8 \\
\hline Formosa & 78,3 & 83,1 & 87,3 & 88,5 & 10,8 & 10,1 & 8,2 & 7,5 & 10,9 & 6,8 & 4,5 & 4,0 \\
\hline Jujuy & 76,4 & 80,0 & 82,8 & 83,8 & 15,6 & 13,7 & 12,2 & 11,8 & 8,0 & 6,3 & 5,0 & 4,4 \\
\hline La Pampa & 76,8 & 76,8 & 77,1 & 77,0 & 20,5 & 21,5 & 21,8 & 21,9 & 2,7 & 1,7 & 1,1 & 1,1 \\
\hline Rioja & 86,1 & 82,8 & 80,7 & 80,9 & 13,2 & 16,5 & 18,5 & 18,2 & 0,7 & 0,7 & 0,7 & 1,0 \\
\hline Mendoza & 80,1 & 82,8 & 85,4 & 86,1 & 14,5 & 12,8 & 11,0 & 10,2 & 5,4 & 4,4 & 3,6 & 3,8 \\
\hline $\mathrm{M}$ & 80,5 & 85,2 & 88,3 & 89,0 & 8,1 & 7,8 & 7,1 & 7,0 & 11,4 & 6,9 & 4,6 & 4,0 \\
\hline Neuquén & 654 & 62,6 & 66,7 & 67,3 & 25,0 & 28,0 & 26,1 & 26,4 & 9,6 & 9,4 & 7,2 & 6,3 \\
\hline Kio Negro & 60,1 & 62,7 & 68,6 & 68,9 & 26,4 & 25,7 & 22,6 & 23,7 & 13,5 & 11,7 & 8,8 & 7,4 \\
\hline Salta & 82,6 & 84,7 & 87,3 & 88,4 & 13,7 & 12,1 & 10,1 & 9,3 & 3,7 & 3,2 & 2,7 & 2,3 \\
\hline San Juan & 89,7 & 91,5 & 92,5 & 92,6 & 7,9 & 6,9 & 6,5 & 6,5 & 2,4 & 1,5 & 1,1 & 0,9 \\
\hline Luis & 81,6 & 76,5 & 73,6 & 72,9 & 17,2 & 22,1 & 25,1 & 25,8 & 1,2 & 1,4 & 1,3 & 1,3 \\
\hline Santa Cruz & 42,6 & 48,5 & 53,8 & 50,8 & 35,6 & 35,8 & 34,2 & 39,7 & 21,8 & 15,8 & 12,0 & 9,5 \\
\hline $\mathrm{Sa}$ & 80,4 & 83,5 & 85,5 & 85,9 & 16,2 & 14,7 & 13,3 & 12,9 & 3,4 & 1,9 & 1,2 & 1,2 \\
\hline Santiago del Estero & 8 & 89,9 & 90,1 & 1 & 10,2 & 8 & 9,7 & , & 0,6 & 0,3 & 0,3 & 3 \\
\hline Tierra del Fuego & 26,5 & 28,9 & 36,3 & 34,8 & 45,1 & 55,8 & 52,6 & 56,3 & 28,4 & 15,3 & 11,1 & 8,9 \\
\hline Tucumán & 88,3 & 90,3 & 91,6 & 91,8 & 10,5 & 9,0 & 7,8 & 7,6 & 1,2 & 0,8 & 0,6 & 0,6 \\
\hline
\end{tabular}

(1) Nacidos en la Argentina que residen en una provincia distinta a la de su nacimiento.

(2) Son la suma de los nacidos en países limítrofes y en países no limítrofes.

Las dos categorías dan cuenta de la migración acumulada hasta cada fecha censal, independientemente de la antigüedad de la migración.

Fuente: Elaboración personal sobre la base de los Censos Nacionales de Población 1980, 1991,2001 y 2010 (INDEC). 
Si analizamos la distribución promedio de los migrantes internos y migrantes extranjeros, a las distintas fechas censales (1980,1991, 2001 y 2010), vemos que la participación de los migrantes internos es mayor a los migrantes externos, y su variabilidad medida a través del coeficiente de variación es más alta (prácticamente el doble). Los migrantes internos son en promedio al 17,6\% durante el periodo 1980-2010, mientras que los migrantes externos son solo $4,8 \%$. Mientras que el primero tiende a mantenerse relativamente estable durante este periodo, el ultimo tiende a descender durante los periodos censales (en el censo 2010 el promedio de participación de migrantes externos es solo de $3,6 \%$ ).

Si en cambio realizamos un análisis a nivel de cada provincia durante las tres décadas podemos destacar los casos de Misiones, Formosa y San Juan, en donde la participación de los migrantes externos está más cercana a la participación de los migrantes internos, siendo esta ultima siempre mayor en todas las provincias. Así mismo, estas tres provincias se encuentran entre la de mayor variabilidad de la participación de los migrantes externos durante el periodo 1980-2010.

Cabe remarcar que la variabilidad de la participación de los migrantes externos es mayor a la de los migrantes internos en todas las provincias, con excepción de las jurisdicciones siguientes, presentadas en orden descendente: Corrientes, San Luis, Chubut, CABA y Catamarca

Las provincias de la región Patagónica, Buenos Aires y CABA se destacan por una alta participación de migrantes internos y externos en su población.

Mientras que Misiones, Formosa, Jujuy y Mendoza presentan altos porcentajes en términos relativos de población migrante externa, mientras que su porcentaje de población migrante interna se encuentra por debajo del promedio.

\section{La heterogeneidad en el mercado laboral entre jurisdicciones}

En primer término, haremos un breve recorrido por la evolución de las tasas netas de actividad a nivel total país. Entre 1960 y 1980, la tasa de actividad tendió a descender de manera suave pasando de 54\% en 1960, a 53\% en 1970 y finalizando en $50 \%$ en 1980. Estos periodos, se destacan por la baja participación en la actividad laboral de la mujer (la tasa neta de actividad femenina se encuentra entre $22 \%$ y $27 \%$ durante este periodo), y de los grupos en edad extrema: los más jóvenes (14 a 19 años) tardan en ingresar al mercado laboral y los de edad más avanzada (65 años y mas) se retiran masivamente del mismo en los últimos años.

En los tres últimos Censos Nacionales 1991, 2001 y 2010, la tasa de actividad se incrementa, $56,7 \%, 57,2 \%$ y $60,9 \%$, respectivamente. La tasa de participación de la mujer en el mercado a partir del Censo de 1991 es superior al 40\% y continua en aumento en los censos siguientes.

Hasta aquí, hemos analizado indicadores correspondientes al promedio nacional. Al tratarse de una medida resumen, se esconden diferencias entre las 
provincias o regiones, como consecuencia de las diversas situaciones productivas que presentan las mismas.

La población de las distintas provincias participa en la actividad económica con diferente intensidad. La brecha entre la provincias con mayor tasa de actividad y la menor es de: 20,9 puntos porcentuales en el censo de 1991 ( se da entre Tierra del Fuego que posee una tasa de actividad de $72,7 \%$ y Tucumán con $51,7 \%$ ), la brecha desciende de manera poco significativa a 18,1 puntos porcentuales en el censo del 2001 (Tierra del Fuego posee la tasa de actividad más alta de 67,5\% y Santiago del Estero la más baja de tan solo 49,5\%) y se mantiene la misma brecha de 18,1 p.p. en el censo del 2010 (entre Tierra del Fuego continuando con la tasa de actividad máxima de 73,5\% y Santiago del Estero con la mínima de 55,5\%). Ver Figura N³.
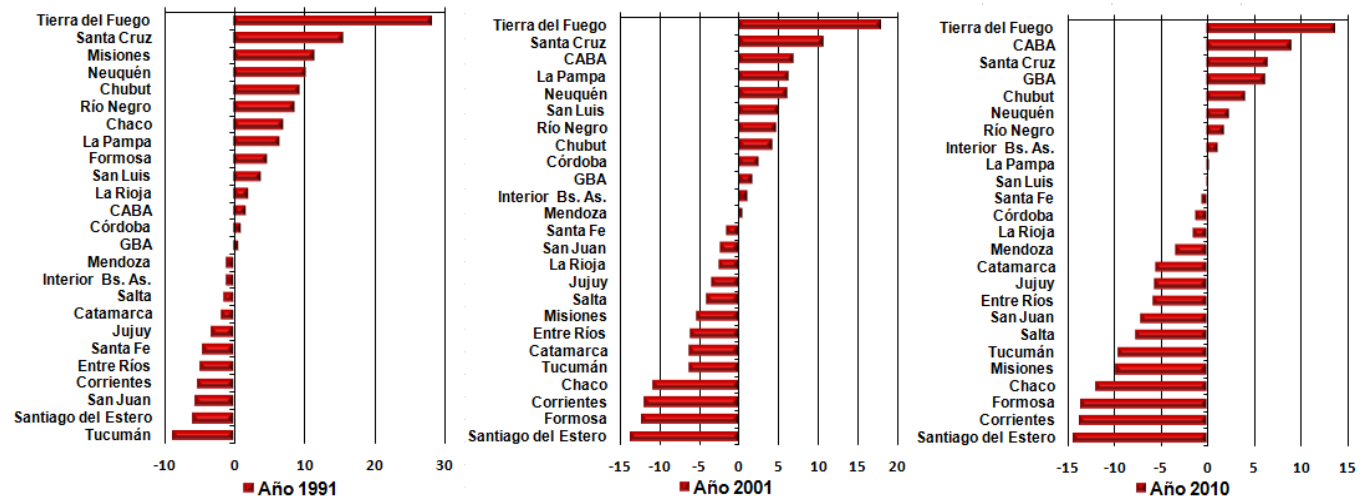

Figura $\mathbf{N}^{\circ}$ 3. Diferencia relativa de la tasa de actividad de cada provincia con respecto al total del país. Años: 1991; 2001 y 2010.

Fuente: Elaboración personal sobre la base de los Censos Nacionales de Población 1991,2001 y 2010 (INDEC).

Estas presentan las características estructurales diferenciales del mercado de trabajo argentino. Si consideramos el promedio de la tasa de actividad por regiones durante el periodo 1991-2010 vemos que: la tasa de actividad promedio del área patagónica es de 65,2\% durante las últimas 3 décadas, la metropolitana es de 62,3\%, la pampeana $59,3 \%$, la región de cuyo $58,8 \%$, la región noroeste $56,2 \%$, y la región noreste $55,8 \%$. La diferencia región Patagonia y la región noroeste, ha sido en el año 1991 de 10,0 puntos porcentuales, y en 2001 y 2010 de 10,8 p.p y 11,6 p.p., respectivamente, entre la región patagónica y la región noreste. Como vemos la tendencia es hacia la divergencia, y también hay cambios en mas variabilidad en la tasa de actividad de las regiones más atrasadas, mientras que la regiones más desarrolladas Patagonia y Metropolitana son más estables.

Los niveles de desocupación muestran una heterogeneidad regional aun superior a la tasa de actividad. El coeficiente de variación de la desocupación provincial del censo 1991 es de 26,3\%, mientras que en los dos últimos censos desciende a 19,4\% 
y $16,3 \%$ (muy superior a los valores del coeficiente de variación de las tasas de actividad provinciales del censo de 1991 en 7,8\%, de 2001 en 7,6\% y de 2010 en 7,5\%).

La brecha máxima entre las provincias con mayor tasa de desocupación y la menor es: 6,0 puntos porcentuales en el censo de 1991 (entre Tucumán que posee una tasa de desocupación de 9,0\% y Chaco con 3,0\%); 20,9 puntos porcentuales en el censo de 2001 (entre el Gran Buenos Aires que posee una tasa de desocupación de 36,4\% y Santa Cruz con 15,5\%) y una brecha de 3,6 p.p. en el censo de 2010 (entre Tucumán que posee una tasa de desocupación de 7,9\% y la Ciudad Autónoma de Buenos Aires con 4,3\%).

A diferencia de lo que sucedía en la tasa de actividad, donde tiende a mantenerse elevados valores en las brechas máximas entre los censos 1991, 2001 y 2010, en el caso de la tasa de desocupación en el año 2001 se produce un quiebre, debido a la disminución abrupta de la demanda de empleo, que obviamente afecta de manera diferencial sobre las distintas provincias. También podemos expresar la diferencia entre la provincia con mayor tasa de desocupación y la menor, mediante la variación relativa, la tasa de desocupación más alta es $199,1 \%$ superior a tasa de desocupación de la provincia con menor desocupación en el año 1991; 134,5\% en el censo de 2001 y $83,8 \%$ en el año 2010 . Ver Figura $N^{\circ} 4$.
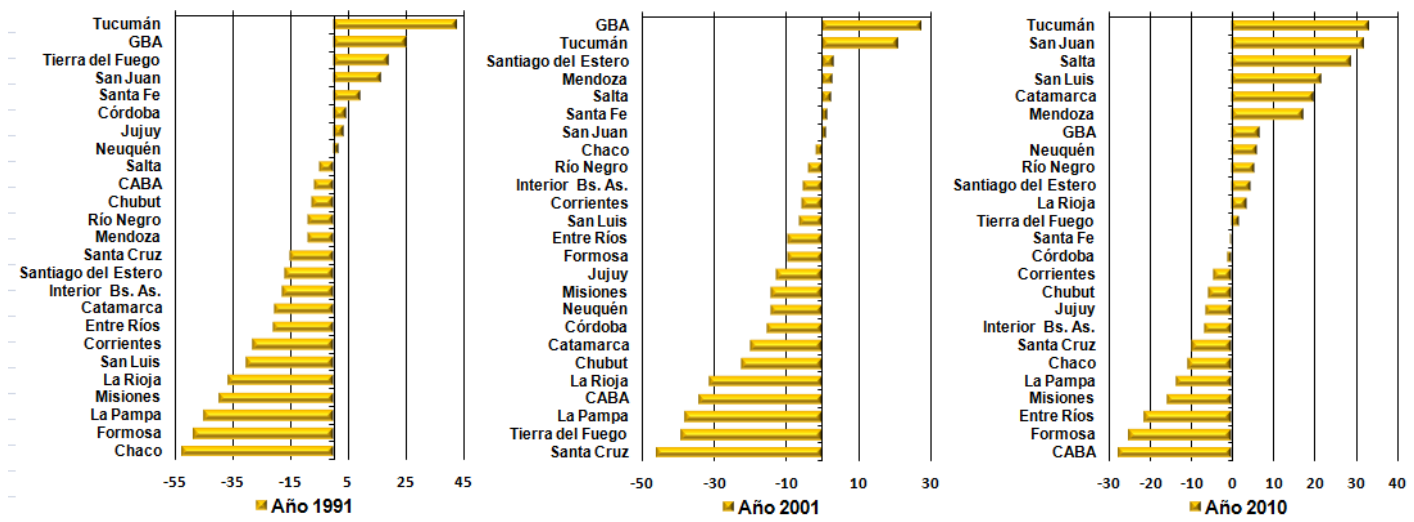

Figura $\mathbf{N}^{\circ}$ 4. Diferencia relativa de la tasa de desocupación de cada provincia con respecto al total del país. Años: 1991; 2001 y 2010.

Fuente: Elaboración personal sobre la base de los Censos Nacionales de Población 1991,2001 y 2010 (INDEC).

Si comparamos los valores de la tasa de actividad y la tasa de desocupación, no encontramos correlación significativa entre ambas. Se destaca un gran heterogeneidad (el coeficiente de determinación $\mathrm{R}^{2}$ es de 0,12). En el año 1991 las provincias que se destacan por alta tasa de actividad y tasa desempleo alta en términos relativos en relación a las 24 provincias, son las siguientes: Tierra del Fuego y Neuquén. Las provincias que presentan la particularidad de tener baja tasa de actividad y alta baja de desempleo son: Tucumán, y San Juan. Como excepción a estas variantes se encuentran Tierra del Fuego, Santa Cruz y Neuquén. 
En el caso del censo 2001 el coeficiente de determinación $\mathrm{R}^{2}$ asciende apenas a 0,27 , por tanto, tampoco podemos decir que existe una relación lineal entre la tasa de actividad y el desempleo. Las provincias que se destacan por una alta tasa de actividad y un bajo desempleo en términos relativos, son: Tierra del Fuego, Santa Cruz, CABA, La Pampa y Tucumán. Las provincias que se presentan baja tasa de actividad y alto desempleo en relación al resto de las provincias son: Santiago del Estero y nuevamente Tucumán.

Para 2010 tampoco existe evidencia empírica de relación entre tasa de actividad y desempleo, ya que el $\mathrm{R}^{2}$ desciende a 0,01 . Las provincias en donde existe alta tasa de actividad y bajo desempleo -en términos relativos en relación al resto de las provincias-, son: CABA y nuevamente Santa Cruz. Las provincias con baja tasa de actividad y alto desempleo son: Tucumán, Salta y San Juan.

\section{Relación entre Desempleo y dinámica migratoria interna. Periodo 1991-2010}

En este apartado veremos en qué medida las amplias desigualdades en el mercado de trabajo, se relacionan con el balance de la migración interna interprovincial durante el periodo 1991-2010. Con el objetivo de poder dilucidar en qué medida los diferenciales en las tasas de desempleo explican las complejidades de los flujos migratorios. Pero antes analicemos los cambios principales en los contextos políticos económicos que ocurrieron durante las tres últimas décadas.

Durante el periodo 1991 a 2001, se establece un modelo económico de matriz neoliberal, basado en las facilidades al capital a través de privatizaciones, tipo de cambio fijo y bajo; flexibilidad laboral, rápida y amplia apertura externa, y concentración económica. Las consecuencias fueron las subas de los niveles de desempleo, subempleo y la informalidad.

El incremento del desempleo en la Argentina, asociado al plan de Convertibilidad, generó la triplicación de la tasa de desocupación entre 1991 y 1995 , debido principalmente a:

- La "Reforma del Estado" (con ejes en la privatización y desregulación) se realizó en forma desordenada, sin el menor interés oficial por parte de los grupos empresarios favorecidos, por el proceso de reinserción de la masa laboral despedida o retirada.

- La apertura externa indiscriminada, favorecida por el tipo de cambio que alentó las importaciones hasta la crisis de 1995, que desaceleró su fuerte crecimiento; sin embargo después de 1996 continuó la avalancha importadora.

- Tasas cada vez más altas para los créditos, haciendo más difícil a las PyMES su financiamiento. Este estrato, que ha sido el más generador de empleo en la Argentina, sufre debilitamiento o desaparición de numerosas unidades (GEJO, MORINA y VELÁZQUEZ, 2000 p. 106).

Estos fenómenos afectaron a casi todas las provincias argentinas, provocando un incremento sustancial de la desocupación. 
La post-convertibilidad, entre el año 2002 y 2010, llegó de la mano de cambios a nivel macroeconómico, como ser un tipo de cambio real alto y de flotación controlada; retenciones, superávit fiscal y una búsqueda de un saldo comercio exterior positivo. Durante el periodo 2002 al 2007 el modelo tuvo un impacto importante en términos de re-industrialización y un alto crecimiento económico. Pasemos a analizar como fue el balance de la migración interna al año 2001, a partir del Tabla III.

Tabla III: Provincias ganadoras y perdedoras de población. Periodo 1996-2001

1996-2001

\begin{tabular}{l|c|c|c|c}
\hline \multicolumn{1}{c}{ Jurisdicción } & Inmigrantes & Emigrantes & Saldo & $\begin{array}{c}\text { TAM de Mig. } \\
\text { Neta (\%) }\end{array}$ \\
\hline La Rioja & 16.777 & 5.778 & $\mathbf{1 0 . 9 9 9}$ & $\mathbf{7 , 3}$ \\
\hline Tierra del Fuego & 13.101 & 9.251 & $\mathbf{3 . 8 5 0}$ & $\mathbf{7 , 2}$ \\
\hline Córdoba & 95.605 & 64.941 & $\mathbf{3 0 . 6 6 4}$ & $\mathbf{6 , 4}$ \\
\hline San Luis & 24.284 & 12.375 & $\mathbf{1 1 . 9 0 9}$ & $\mathbf{6 , 2}$ \\
\hline Santa Cruz & 18.810 & 12.875 & $\mathbf{5 . 9 3 5}$ & $\mathbf{5 , 3}$ \\
\hline Catamarca & 13.879 & 8.415 & $\mathbf{5 . 4 6 4}$ & $\mathbf{3 , 3}$ \\
\hline Neuquén & 28.162 & 21.060 & $\mathbf{7 . 1 0 2}$ & $\mathbf{2 , 9}$ \\
\hline Buenos Aires & 405.287 & 279.131 & $\mathbf{1 2 6 . 1 5 6}$ & $\mathbf{1 , 8}$ \\
\hline La Pampa & 13.798 & 11.821 & $\mathbf{1 . 9 7 7}$ & $\mathbf{1 , 4}$ \\
\hline Chubut & 24.311 & 19.959 & $\mathbf{4 . 3 5 2}$ & $\mathbf{1 , 0}$ \\
\hline San Juan & 14.903 & 12.839 & $\mathbf{2 . 0 6 4}$ & $\mathbf{0 , 7}$ \\
\hline Santa Fe & 59.799 & 53.013 & $\mathbf{6 . 7 8 6}$ & $\mathbf{0 , 5}$ \\
\hline Mendoza & 39.005 & 35.508 & $\mathbf{3 . 4 9 7}$ & $\mathbf{0 , 4}$ \\
\hline Tucumán & 27.065 & 26.878 & $\mathbf{1 8 7}$ & $\mathbf{0 , 0}$ \\
\hline Salta & 32.440 & 32.360 & $\mathbf{8 0}$ & $\mathbf{0 , 0}$ \\
\hline
\end{tabular}

\section{Perdieron población}

\begin{tabular}{l|c|c|c|c}
\hline \multicolumn{1}{c|}{ Jurisdicción } & Inmigrantes & Emigrantes & Saldo & $\begin{array}{c}\text { TAM de Mig. } \\
\text { Neta (\%o) }\end{array}$ \\
\hline Corrientes & 29.912 & 34.488 & $\mathbf{- 4 . 5 7 6}$ & $\mathbf{- 2 , 0}$ \\
\hline Formosa & 11.875 & 14.968 & $\mathbf{- 3 . 0 9 3}$ & $\mathbf{- 1 , 3}$ \\
\hline Jujuy & 20.091 & 23.335 & $\mathbf{- 3 . 2 4 4}$ & $\mathbf{- 1 , 1}$ \\
\hline Río Negro & 27.841 & 30.852 & $\mathbf{- 3 . 0 1 1}$ & $\mathbf{- 1 , 1}$ \\
\hline Santiago del Estero & 20.276 & 23.972 & $\mathbf{- 3 . 6 9 6}$ & $\mathbf{- 0 , 9}$ \\
\hline Misiones & 27.600 & 31.510 & $\mathbf{- 3 . 9 1 0}$ & $\mathbf{- 0 , 8}$ \\
\hline Chaco & 21.954 & 32.275 & $\mathbf{- 1 0 . 3 2 1}$ & $\mathbf{- 0 , 7}$ \\
\hline Entre Ríos & 33.593 & 34.607 & $\mathbf{- 1 . 0 1 4}$ & $\mathbf{- 0 , 2}$ \\
\hline CABA & 253.677 & 254.522 & $\mathbf{- 8 4 5}$ & $\mathbf{- 0 , 1}$ \\
\hline
\end{tabular}

Fuente: Elaboración personal sobre la base del Censo Nacional de Población 2001 (INDEC). 
En primer lugar vemos que las provincias que tuvieron comportamiento migratorio expulsor durante el periodo 1996-2001, presentaban en promedio menor tasa de desempleo, mientras que la tasa de actividad era apenas inferior. Por tanto, este desplazamiento de mano de obra a las provincias receptoras, exacerba las dificultades existentes en las regiones de destino.

Aunque si pasamos a mirar cada provincia en particular, durante el periodo 1996-2001, se visibiliza el nivel de heterogeneidad existente.

De las 15 provincias que han tenido saldo neto migratorio positivo, en siete de ellas -Tierra del Fuego, Chubut, La Rioja, Catamarca, Santa Cruz, Neuquén y Salta-, la tasa de actividad ha disminuido entre el año 1991 y el 2001, y además en los casos de la provincia de La Rioja y Salta el desempleo ha aumentado por encima de la media.

En las ocho provincias restantes que tuvieron saldo migratorio positivo y aumento de la tasa de actividad, en tres de ellas también se generó un aumento del desempleo, estas son San Luis, Mendoza y La Pampa.

Con respecto a las 9 provincias que han tenido migratorio negativo, sólo CABA y Jujuy - con un mínima variación positiva- han tenido aumento de la tasa de actividad y caída del desempleo por debajo de la media; mientras que en las siete provincias restantes se ha producido un caída de la tasa de actividad y también aumento del desempleo con respecto al aumento del crecimiento promedio - con excepción de Rio Negro en donde el desempleo crece pero en menor medida que la media.

En síntesis en las provincias receptoras, la tasa de actividad ha caído menos que en las provincias expulsoras, por tanto, el proceso de migración de los trabajadores agravo aún más la situación de las provincias de origen, mientras que el desempleo aumentó menos en estas provincias. Haciendo un análisis contrafáctico, tal vez las personas hubiesen logrado conseguir empleo si permanecían en sus provincias de origen en lugar de migrar.

Las provincias que tuvieron saldo migratorio neto positivo han sido también 15 durante el periodo 2005-2010, es decir, las que han ganado población. Doce son las mismas que las del quinquenio 1996-2001, mientras que otras tres han cambiado. En este quinquenio Rio Negro, Entre Ríos y CABA han presentado un saldo migratorio neto positivo, mientras que Salta, San juan y Catamarca se han transformado en expulsoras.

Tanto las quince provincias que han tenido salto neto positivo, como las nueve que han tenido saldo negativo, han logrado una disminución con baja en la tasa de desempleo y aumento de la tasa de actividad. Pero en las provincias expulsoras, contradictoriamente han descendido más en promedio las tasas de desempleo que las provincias receptoras. Mientras que en la tasa de actividad sucede lo contrario, crece más la tasa de actividad en las provincias receptoras que en las expulsoras. Las migraciones reducen las potencialidades de crecimiento de las provincias expulsoras, y generan presión sobre el mercado laboral en las provincias receptoras. El desplazamiento del trabajo hacia las regiones de mayor desarrollo relativo, generó empeoramiento de los índices de desempleo. 
Tabla IV: Provincias ganadoras y perdedoras de población. Periodo 2005-2010

2005-2010

\begin{tabular}{l|c|c|c|c}
\hline \multicolumn{5}{c}{ Ganaron población } \\
\hline Jurisdicción & Inmigrantes & Emigrantes & Saldo & $\begin{array}{c}\text { TAM de Mig. } \\
\text { Neta (\%) }\end{array}$ \\
\hline Buenos Aires & 572.128 & 307.981 & $\mathbf{2 6 4 . 1 4 7}$ & $\mathbf{3 , 7 6}$ \\
\hline Córdoba & 110.315 & 65.350 & $\mathbf{4 4 . 9 6 5}$ & $\mathbf{3 , 0 3}$ \\
\hline Santa Cruz & 38.085 & 16.572 & $\mathbf{2 1 . 5 1 3}$ & $\mathbf{1 9 , 0 8}$ \\
\hline Santa Fe & 74.767 & 56.596 & $\mathbf{1 8 . 1 7 1}$ & $\mathbf{1 , 2 5}$ \\
\hline Mendoza & 49.455 & 33.952 & $\mathbf{1 5 . 5 0 3}$ & $\mathbf{1 , 9 9}$ \\
\hline Río Negro & 40.097 & 27.792 & $\mathbf{1 2 . 3 0 5}$ & $\mathbf{4 , 3 4}$ \\
\hline Tierra del Fuego & 21.176 & 10.059 & $\mathbf{1 1 . 1 1 7}$ & $\mathbf{2 0 , 9 1}$ \\
\hline CABA & 301.775 & 293.000 & $\mathbf{8 . 7 7 5}$ & $\mathbf{0 , 6 6}$ \\
\hline Chubut & 40.896 & 33.178 & $\mathbf{7 . 7 1 8}$ & $\mathbf{3 , 4 4}$ \\
\hline San Luis & 22.627 & 15.962 & $\mathbf{6 . 6 6 5}$ & $\mathbf{3 , 4 5}$ \\
\hline Neuquén & 32.178 & 26.384 & $\mathbf{5 . 7 9 4}$ & $\mathbf{2 , 3 7}$ \\
\hline La Rioja & 11.593 & 7.961 & $\mathbf{3 . 6 3 2}$ & $\mathbf{2 , 4 2}$ \\
\hline Entre Ríos & 37.887 & 35.282 & $\mathbf{2 . 6 0 5}$ & $\mathbf{0 , 4 6}$ \\
\hline La Pampa & 13.646 & 12.465 & $\mathbf{1 . 1 8 1}$ & $\mathbf{0 , 8 2}$ \\
\hline Tucumán & 26.609 & 25.846 & $\mathbf{7 6 3}$ & $\mathbf{0 , 1 2}$ \\
\hline & \multicolumn{2}{|c|}{ Perdieron población } & & \\
\hline Jurisdicción & Inmigrantes & Emigrantes & Saldo & TAM de Mig. \\
\hline Chaco & 21.057 & 35.576 & $\mathbf{- 1 4 . 5 1 9}$ & $\mathbf{- 3 , 0 2}$ \\
\hline Misiones & 31.165 & 44.513 & $\mathbf{- 1 3 . 3 4 8}$ & $\mathbf{- 2 , 7 1}$ \\
\hline Formosa & 13.473 & 26.400 & $\mathbf{- 1 2 . 9 2 7}$ & $\mathbf{- 5 , 3 4}$ \\
\hline Santiago del Estero & 18.807 & 30.835 & $\mathbf{- 1 2 . 0 2 8}$ & $\mathbf{- 3 , 0 5}$ \\
\hline Salta & 31.919 & 39.601 & $\mathbf{- 7 . 6 8 2}$ & $\mathbf{- 1 , 4 2}$ \\
\hline Corrientes & 30.381 & 35.148 & $\mathbf{- 4 . 7 6 7}$ & $\mathbf{- 1 , 0 6}$ \\
\hline Catamarca & 6.666 & 10.551 & $\mathbf{- 3 . 8 8 5}$ & $\mathbf{- 2 , 3 4}$ \\
\hline Jujuy & 21.333 & 24.319 & $\mathbf{- 2 . 9 8 6}$ & $\mathbf{- 0 , 9 8}$ \\
\hline San Juan & 12.390 & 12.661 & $\mathbf{- 2 7 1}$ & $\mathbf{- 0 , 0 9}$ \\
\hline & & &
\end{tabular}

Fuente: Elaboración personal sobre la base del Censo Nacional de Población 2010 (INDEC).

Dentro de las 15 provincias que tuvieron comportamiento migratorio receptivo, solo en seis ha habido incremento de la tasa de actividad por encima del promedio, y dentro de esas siete solo en cinco también ha descendido el desempleo por encima de la media-en Chubut y en la Rioja, ha aumentado la tasa de actividad por encima de media pero no ha descendido por encima del descenso promedio de la tasa de desocupación. Las nueve provincias restantes que tuvieron saldo migratorio positivo, han tenido aumento de la tasa de actividad pero por debajo del promedio y también descenso de la 
tasa de desocupación por debajo del promedio - con excepción de los dos provincias en los cuales el descenso del desempleo fue superior a la media-, estas fueron Rio Negro y Tucumán.

Respecto de las 9 provincias que tuvieron saldo migratorio expulsor, en cuatro de ellas se ha producido aumento de la tasa de actividad por encima del promedio Catamarca ,Chaco, Formosa y Santiago del Estero- y también descenso de la tasa de desempleo por encima de la media en todas ellas, menos en Catamarca. En las cinco provincias restantes que tuvieron un saldo migratorio neto negativo, se ha verificado un aumento de la tasa de actividad por debajo del promedio, y sólo dos de ellas tuvieron descenso de la tasa de desocupación por debajo de la media.

En términos históricos Buenos Aires, Chubut, Neuquén, Tierra del Fuego y Santa Cruz que han sido las provincias que más población han recibido históricamente, continúan haciéndolo hasta el año 2010, con excepción de Rio Negro.

Las provincias que históricamente han tenido saldos migratorios negativos, como ser La Pampa, Córdoba, La Rioja y Catamarca (solo en la década del noventa), este de flujo migratorio puede explicarse por las menores tasas de desempleo en el año 1991. Si bien las tasas de estas cuatro provincias se elevaron, en términos relativos continuaron estando dentro de las de menores tasas de desocupación.

En los casos de La Rioja y Catamarca, este hecho se debe a que han accedido a los planes de la promoción industrial. Sí bien esta última provincia lo hizo más tarde y, por los factores de localización, el impacto de este proceso durante los ochenta fue menor.

Las últimas tres provincias que tuvieron saldo migratorio neto positivo durante el periodo 1996-2001 pero que su saldo migratorio neto histórico hasta el año 2001 había sido negativo, son San Juan, San Luis y Santa Fe. El saldo migratorio neto positivo estaría más explicado, por el menor descenso en términos relativos en sus niveles de tasa de actividad. Si bien durante la década del noventa todas las provincias han reducido su tasa de actividad, estas tres provincias han avanzado posiciones dentro del ranking nacional al año 2001. En el caso de San Luis este menor descenso relativo en la tasa de actividad está vinculado al régimen de promoción industrial llevado adelante a partir de la década del ochenta.

Durante el proceso migratorio del periodo 2005-2010, en el caso de La Rioja que también había tenido saldo migratorio neto positivo durante la década del noventa, y que no se trata de un provincia con alto porcentaje de población no migrante, podemos inferir que el saldo migratorio positivo puede deberse a cierta inercia de las corrientes migratorias del pasado (igualmente tenemos un descenso de 7,3\%o en el quinquenio 1996-2001 a 2,4\%o en el quinquenio 2005-2010).

Catamarca y San Juan que han sido provincias expulsoras en términos históricos, y que durante el periodo 1996-2001 han tenido saldo migratorio positivo, vuelven a su tendencia histórica presentando un saldo migratorio negativo durante el quinquenio 2005-2010. Podemos apreciar en el cuadro $\mathrm{N}^{\circ} 2$ el aumento del crecimiento de la participación de la población no migrante, con lo cual podemos inferir que se ha 
generado un retorno de los emigrantes del periodo 1996-2001 a sus provincias de origen. Este retorno es el que explicaría el bajo descenso de la tasa de desocupación con texto al descenso promedio del periodo 2001-2010. Ambas provincias si bien han aumentado la tasa de actividad en relación al 2001, se encuentran en términos relativos en valores inferiores a la media nacional para el año 2010.

San Luis y Santa Fe, continúan con saldo migratorio neto positivo al igual que en la década del noventa.

Sin embargo en San Luis el saldo migratorio neto fue muy inferior al del periodo 1996-2001 (6,1\%o durante el quinquenio 1996-2001 y 3,4\%o durante el quinquenio 2005-2010. Mientras que en el caso de Santa Fe, la tasa anual del saldo migratorio neto cada 1000 habitantes era muy baja durante el quinquenio 1996-2001 de tan sólo $0,5 \%$, esta se eleva a 1,2\%o en el quinquenio 2005-2010, este aumento se debe a que durante la década del noventa Santa Fe tuvo un crecimiento de la tasa de actividad, y el ingreso de esta demanda de mano de obra durante el periodo 2001-2010 se refleja en el aumento significativo de la tasa de actividad

Se destacan Chaco, Corrientes, Jujuy, Santiago del Estero , Misiones , Formosa, y CABA- con excepción del último periodo que tuvo una tasa de $0,6 \%$ ), por ser unidades que históricamente fueron expulsoras de población (sobre todo en el caso de las dos primeras provincias cuya inserción estuvo dada históricamente por su condición de proveedoras de mano de obra para procesos extrarregionales) y que continuaron siéndolo durante la década del noventa, en el periodo 2001-2010 logran revertir esta tendencia.

En síntesis, el grupo de provincias más receptoras (Santa cruz, Tierra del Fuego, Chubut y Neuquén, con excepción de Buenos Aires) son las que menos han sufrido el incremento de la desocupación del periodo 1991-2001. Mientras que durante el periodo 2001-2010 las provincias que más han reducido el desempleo en términos relativos han sido en mayor medida las que históricamente fueron expulsoras como Formosa, Santiago del Estero, Chaco, Corrientes y las que más han aumentado la tasa de actividad, y a pesar de eso han continuado siendo áreas de expulsión.

\section{Conclusiones}

A lo largo del trabajo hemos visto, que las desigualdades regionales en la Argentina lejos están de solucionarse por el simple accionar del mercado. Los comportamientos migratorios entre las provincias presentan características más bien estructurales. Los desplazamientos de los trabajadores, entre las provincias del país, empeoran las condiciones iniciales del mercado laboral, y son responsables, en cierta medida, de la perpetuación de las asimetrías entre las regiones más desarrolladas y activas y las más postergadas.

Las teorías afines a la lógica del "mercado" consideran que la libre movilidad de los factores, generaría una nivelación entre los mercados laborales de las distintas provincias. En cambio los datos de la realidad muestran características estructurales durante las últimas tres décadas. 
La tasa de actividad por regiones durante el periodo 1991-2010 nos muestra la siguiente heterogeneidad en el territorio: en el área patagónica es de 65,2\%, en la región metropolitana es de $62,3 \%$, en la pampeana $59,3 \%$, en la región de cuyo $58,8 \%$, la región noroeste $56,2 \%$, y la región noreste $55,8 \%$. La diferencia entre la región con mayor actividad la Patagonia y la de menor actividad, que es región noroeste, ha sido en el año 1991 de 10,0 puntos porcentuales, y en los años 2001 y 2010 de 10,8 p.p y 11,6 p.p., respectivamente- entre la región con mayor actividad que es el área patagónica y la región noreste-. Hemos visto que la migración es uno de los medios que posibilita el sostenimiento de estas brechas en la actividad entre las diferentes regiones, retroalimentando el proceso de desigualdad.

Los niveles de desocupación muestran una heterogeneidad regional aún superior a la tasa de actividad. La tendencia divergente, se sucede década tras década. El resultado de la dinámica migratoria, incrementa la variabilidad en la tasa de actividad de las regiones más atrasadas, mientras que hacia las regiones de mayor desarrollo relativo, generó empeoramiento de los índices de desempleo en los lugares de destino. En la tasa de actividad sucede lo contrario, crece más la tasa de actividad en las provincias receptoras que en las expulsoras.

Hemos corroborado, que durante el periodo 1990-2010, los valores de la tasa de actividad y la tasa de desocupación, no presentan ninguna correlación significativa.

Vemos que las propias señales de mercado están lejos está de garantizar una asignación eficiente del factor trabajo, tal como sugiere la lógica neoclásica.

\section{Referencias}

ARGENTINA: Censo Nacional de Población, Hogares y Vivienda 1991. INDEC. Buenos Aires, 1994.

ARGENTINA: Encuesta Permanente de Hogares 2001. INDEC. Buenos Aires, 2002.

ARGENTINA: Natalidad y Mortalidad por División Político-Territorial, 2000.

Dirección de Estadísticas Socio-Sanitarias. Ministerio de Salud. Buenos Aires.

ASTORI, Danilo: Controversias sobre el Agro Latinoamericano. Un Análisis

Crítico. México, Consejo Latinoamericano de Ciencias Sociales, 1982.

BENKO, George: Economia, Espaço e Globalização na Aurora do Século XXI. São Paulo, Hucitec, 1996.

CEÑA DELGADO, Fernando: "Planteamientos económicos del desarrollo rural: una perspectiva histórica”. En RAMOS, E; CRUZ, J. (coord.). Hacia un Nuevo Sistema Rural. Madrid, Editorial Ariel, 1995. Pág. 94-103.

DE MATTOS, Carlos: "Modelos de crecimiento endógeno y divergencia interregional, ¿nuevos caminos para la gestión regional?’. Instituto de Estudios Urbanos. Pontificia Universidad Católica de Chile. Santiago de Chile, 1996. 
GEJO, Omar; MORINA, Jorge; VELÁZQUEZ, Guillermo: “Economía y territorio en Argentina 1975-2000. La violencia de los de arriba”. En Estudios Socioterritoriales. Revista de Geografía, Año I, n. 1. Centro de Investigaciones Geográficas. Tandil, 2000. Pág. 97-116.

HOLLAND, Stuart: “Las teorías del desequilibrio regional”. Documento de Trabajo. Instituto Interamericano de Planificación Económica y Social, 1976.

MÉNDEZ, Ricardo: Geografía Económica. La Lógica Espacial del Capitalismo Global. Editorial Ariel. Barcelona, 1997.

MYRDAL, Gunnard: Teoría Económica y Regiones Subdesarrolladas. Fondo de Cultura Económica. México, 1957.

ROFMAN, Alejandro: Desigualdades Regionales y Concentración Económica. El Caso Argentino. Sociedad Interamericana de Planificación. Buenos Aires, 1974.

SANTOS, Milton: O Espaco Dividido. Os Dois Circuitos da Economia Urbana dos Países Subdesenvolvidos. Colecão o Ciencias Sociales. São Paulo, 1979.

SILVEIRA, María Laura: Um País, uma Regiao. Fim de Século e Modernidade na Argentina. FAPESP; LABOPLAN-USP. São Paulo, 1999.

VELÁZQUEZ, Guillermo: Geografía, Calidad de Vida y Fragmentación en la Argentina de los Noventa. Análisis Regional y Departamental utilizando SIG's. CIG. Universidad Nacional del Centro de la Provincia de Buenos Aires. Tandil, 2001.

VELÁZQUEZ, Guillermo; GÓMEZ LENDE, Sebastián: "Migraciones interprovinciales y diferenciación regional en la Argentina (1991-2001)”. En Jornadas Nacionales sobre la Región. Un Ámbito para la Planificación y la Acción. Neuquén. Universidad del Comahue. (CD Rom), 2002.

Fernando Ariel Manzano

Investigador y Docente de la Universidad Nacional de Moreno. Doctorando en Demografía (Universidad Nacional de Córdoba-Argentina). Licenciado en Economía (Universidad de Buenos Aires-Argentina). Licenciado en Sociología (Universidad de Buenos Aires-Argentina).

Email: fernando14979@hotmail.com

Guillermo Ángel Velázquez

Investigador Superior CONICET. Profesor Titular UNCPBA. Vice Director Instituto de Geografía, Historia y Ciencias Sociales (CONICET/UNCPBA). Campus Universitario. Paraje Arroyo Seco (7000) Tandil.

Email: gvelaz@fch.unicen.edu.ar

Recebido para publicação em fevereiro de 2015

Aprovado para publicação em abril de 2015 